\title{
Optimization of the Efficiency of a Michell-Banki Turbine Through the Variation of Its Geometrical Parameters Using a PSO Algorith
}

\author{
A. J. PEREZ-RODRIGUEZ \\ Departamento de mecatrónica y electromecánica \\ Instituto Tecnológico Metropolitano \\ Cra. 74d \#732, Medellín, Antioquia \\ COLOMBIA \\ J. SIERRA-DEL RIO \\ Departamento de Mecatrónica y Electromecánica \\ Instituto Tecnológico Metropolitano \\ Cra. 74d \#732, Medellín, Antioquia \\ COLOMBIA \\ L. F. GRISALES-NOREÑA \\ Facultad de Ingeniería \\ Institución Universitario Pascual Bravo \\ Cl. 73 \#\# 73a-226, Medellín, Antioquia \\ COLOMBIA \\ S. GALVIS \\ Departamento de Mecatrónica y Electromecánica \\ Instituto Tecnológico Metropolitano \\ Cra. 74d \#732, Medellín, Antioquia \\ COLOMBIA
}

\begin{abstract}
Small-scale hydropower generation can satisfy the needs of communities located near natural sources of flowing water. The operating conditions of a Michell-Banki Turbine (MBT) are relatively easier to meet than those of other types of turbine, making it useful in places where other devices are not suitable. Moreover, MBT efficiency is almost invariable with respect to flow rate conditions. Nevertheless, such efficiency commonly ranges between $70 \%$ and $85 \%$, which is lower than that of other water turbines like Turgo, Pelton, or Francis turbine. The objective of this work is to determine the maximum theoretical efficiency of an MBT and its associated geometrical parameters by implementing Particle Swarm Optimization. The results show a higher effectiveness of the mathematical formulation compared with other cases from literature and show the performance of the optimization method proposed in this study in terms of solution and processing time. Finally, a maximum MBT efficiency of $93.3 \%$ was achieved.
\end{abstract}

Key-Words: - PSO, cross-flow turbine, efficiency, hydropower, metaheuristic optimization, Velocity triangles

Received: January 13, 2021. Revised: July 23, 2021. Accepted: July 25, 2021. Published: August 2,

2021.

\section{Introduction}

Large-scale electricity generation from renewable sources may contribute to the economic development of Non-Interconnected Zones (NIZs). However, as a result of high generation and distribution costs, supplying electricity to those areas from big facilities is infeasible [1]. For that reason, their inhabitants resort to conventional generation technologies such as carbon-based fuels, which have been associated with genotoxic and carcinogenic risks to human health [2]. Small Hydro Power Plants (SHPPs) have been presented as low-cost, low environmental 
impact solutions to supply electricity to NIZs; more specifically, Michell-Banki Turbines (MBTs) have drawn great interest because they are easy to install, manufacture, and maintain, avoiding considerable civil works to store water and safety devices used in other types of turbines such as Pelton, Turgo, and Francis [3]. MBTs are used as energy recovery systems in Water Distribution Networks (WDNs), with better performance and lower costs than current systems that implement Pressure Release Valves (PRVs) and Pumps As Turbines (PATs) [4], which means that MBTs offer wide applicability as lowcost solutions to harness energy.

The efficiency of MBTs usually ranges between $70 \%$ and $85 \%$, and it does not vary significantly when flow rate conditions change [5]. Furthermore, MBTs require relatively limited flow rate $(Q)$ and head $(H)$ (Figure 1), which represents the main advantage of this technology.

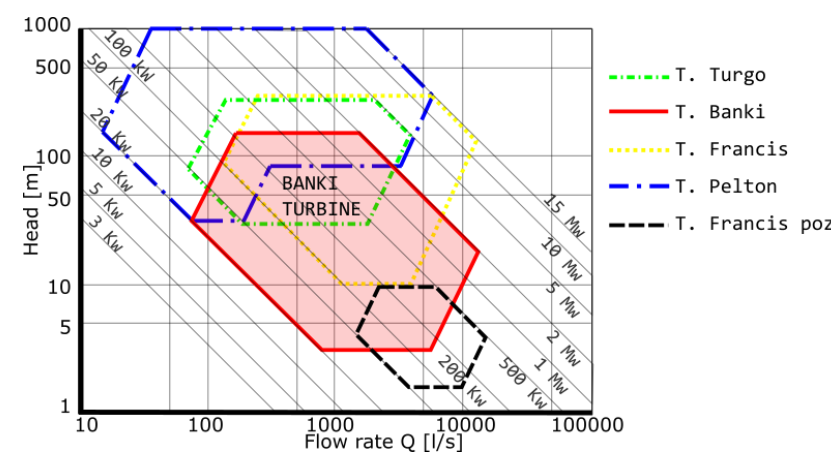

Figure 1. Operating conditions of different types of water turbines [6].

Different mathematical formulations have been developed in order to size the elements of the highest impact on efficiency of MBTs and characterize the flow conditions inside the turbomachine. In 1949, C. A. Mockmore and F. Merryfield presented the first mathematical model with experimental validation that could be used to size an MBT according to the conditions of the site, defined by flow rate and head [7].

Later, in order to improve the MBT efficiency by changing its operating conditions, different experimental studies concluded that flow rate and net head have no significant effect on the efficiency of the turbine, unlike the geometric parameters that constitute its runner and nozzle [8][9]. According to other authors, the velocity ratio, determined by the ratio between the tangential velocity of the runner and the velocity of the water at the nozzle outlet, represents an important factor in the configuration of an MBT; in those cases, maximum efficiencies were found at velocity ratios between 0.5 and 0.6 [8][10]. Nevertheless, the velocity ratio should be established according to the flow conditions in order to avoid cavitation when the flow hits the runner at second stage [11].

In addition to their operating parameters, the geometric configuration of MBTs has been studied, adopting different methodologies, to improve their efficiency by varying the geometry of the nozzle, runner, and blades. Numerical (Computer Fluid Dynamics, CFD) and experimental simulations have been implemented to determine the influence of the geometric parameters of the nozzle and the runner on MBT efficiency; for example, when a guide vane is used, the performance of the nozzle changes[12], showing an improvement of 5.33\%. Other authors have proposed the implementation of two nozzles in the turbine to enhance its efficiency [13] and presented mathematical formulations that can define the ideal curvature of the nozzle, specifically the back wall that redirects water to the runner, ensuring uniform velocity and angle of attack along the runner inlet. The substantial influence of the geometry of the nozzle on MBT efficiency is mainly determined by the angle of attack of the fluid with respect to the runner [14][15].

Regarding the design of the runner, the geometry of the blades represents an important geometric factor, which has been demonstrated to have an influence between $31.7 \%$ and $86 \%$ on MBT efficiency [16]-[18]. Moreover, the number of blades, usually between 15 and 45 , plays an important role in the performance of an MBT [19]. In most cases, the maximum recommended number of blades is directly related to their geometry, especially their thickness: the thicker the blades, the lower their number, and vice versa. Finally, the position of the blades is determined by the angles of attack $(\alpha)$ of water, the external angle of the blade $(\beta)$, and the aspect ratio of the runner, defined as the ratio between its inner and outer diameters; such variables influence the efficiency of an MBT, which ranges between $60 \%$ and $90 \%$ [20]-[22].

Experimental results provide a real description of the operation of an MBT with preestablished flow conditions; they enable researchers to calculate operating correlations based on empirical modeling and thus confirm the effect of geometric or operating parameters on the performance of the turbine. However, experimental analyses would be infeasible in this case because changing the geometric parameters of an MBT an indefinite number of times would entail excessively high implementation costs. CFD can overcome that limitation by implementing numerical solutions of the proposed domains and varying the geometric parameters in order to estimate their effect on MBT efficiency [23]. Although they 
are efficient, fast, and lower cost than their experimental counterparts, numerical models sometimes require great computational capacity in order to estimate the physical phenomena that take place in different dynamic flow systems.

For that reason, mathematical formulations and optimization techniques have been employed in recent years to reduce processing times and find adequate solutions to design problems, thus limiting the complexity and computational effort associated with the estimation of the effect of geometric and operating variables on MBT efficiency [20]. Among the optimization methods employed in the specialized literature, metaheuristic techniques have drawn great attention [24] and provided high-quality solutions to engineering problems [24]-[27] (e.g., designing power generation turbines [28], [29]) with satisfactory design results and reduced computational loads. Particle Swarm Optimization (PSO) is one of the most commonly employed metaheuristic techniques in the literature to solve continuous problems [24], which is the case analyzed in this work. PSO is based on the behavior of groups of animals looking for food sources, and it offers low mathematical and programming complexity [30]. This technique has also been implemented to determine the configuration of $\alpha$ and $\beta$ in order to find the best hydraulic performance of the MBT [20], [21]. In those cases, however, the mathematical formulations proposed by the authors assumed the inlet and outlet blade angles to be equal. For that reason, their mathematical models do not adequately represent the physics of the model under analysis.

Therefore, this work highlights the importance of proposing new MBT design methodologies that adequately represent the physics of the problem and implement efficient solution methods that entail a low computational cost. This study has two objectives: (i) to determine the $\alpha$ and $\beta$ angles that guarantee the maximum MBT efficiency by implementing a PSO method based on the moment of momentum equation and (ii) to validate the results obtained with respect to experimental data reported in the literature.

Section 3 presents a brief theoretical framework of the operation of an MBT and the physical behavior of water inside the turbine. Section 4 describes the optimization method proposed in this work to solve the problem. Subsequently, Section 5 details the methodology and the parameters implemented to address the problem. Section 6 reports the results, and Section 7 draws the conclusions.

\section{Theoretical Framework}

An MBT is a crossflow turbine composed of a runner, a nozzle, a guide vane, and a casing as shown in Figure 2. The runner is a wheel defined by inner and outer diameters that harnesses $70 \%$ of the energy in the water stream during the first stage of the process (it means, the first time the water makes the runner work) and 30\% during the second stage (it means, the second time the water makes the runner work) [14]. Multiple related parameters have been studied in the literature to improve the efficiency of such turbine: the angle of attack of water (defined by the internal and external angles of the blade with respect to the tangent of the runner), the design of the upper casing of the nozzle (which guarantees that the flow enters the runner uniformly), the number of blades, and the geometric profile of the blades.

a)

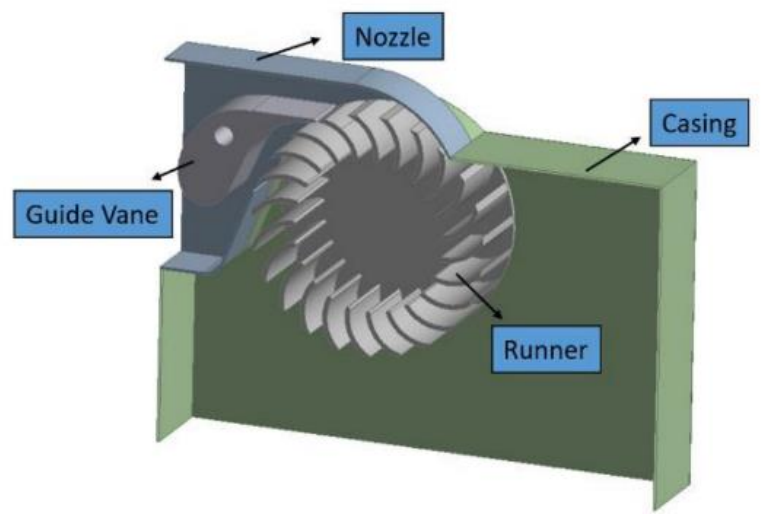

b)

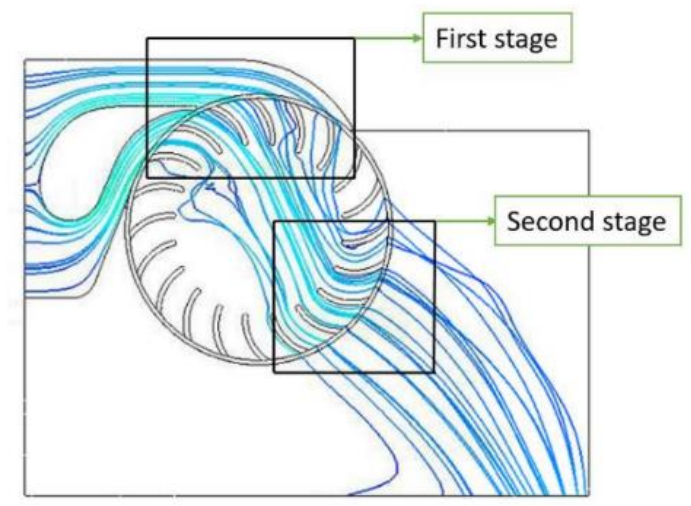

Figure 2. a) Michell-Banki Turbine assembly. b) Energy transfer in the first and second stages [19].

\subsection{Geometrical Formulation}

Different models can be used to size and determine the geometry of the components of an MBT based on flow rate and net head conditions. The design of the runner is commonly derived from the velocity triangle described in Figure 3, where regions 1 and 2 represent the inlet and outlet flow through the runner during the first stage respectively; in turn, regions 3 and 4 correspond to the inlet and outlet flow in the second stage, respectively. This geometric analysis will be subsequently used for the physical formulation of the behavior of water inside the turbine. 
a)

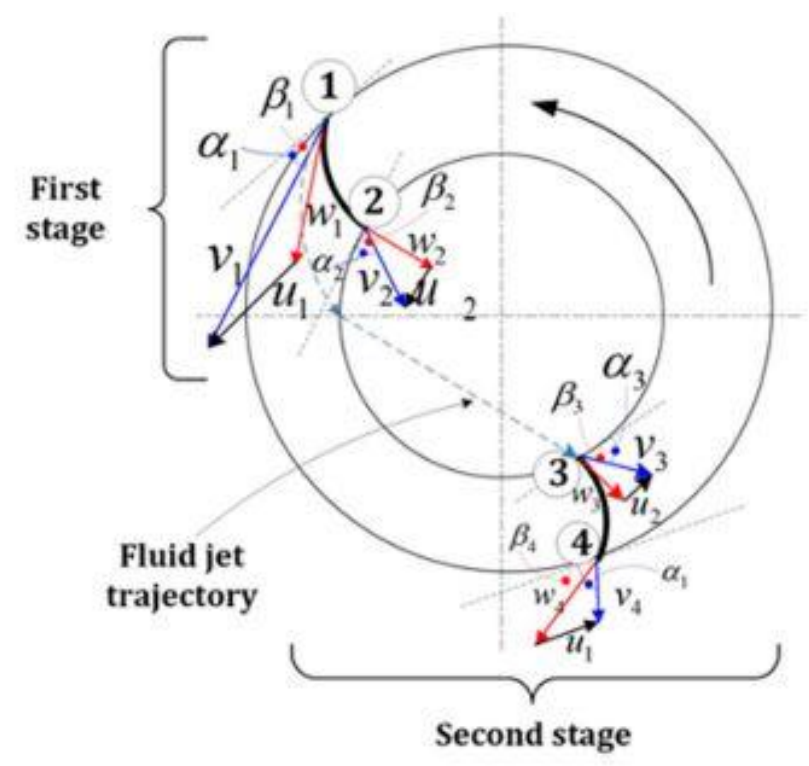

b)
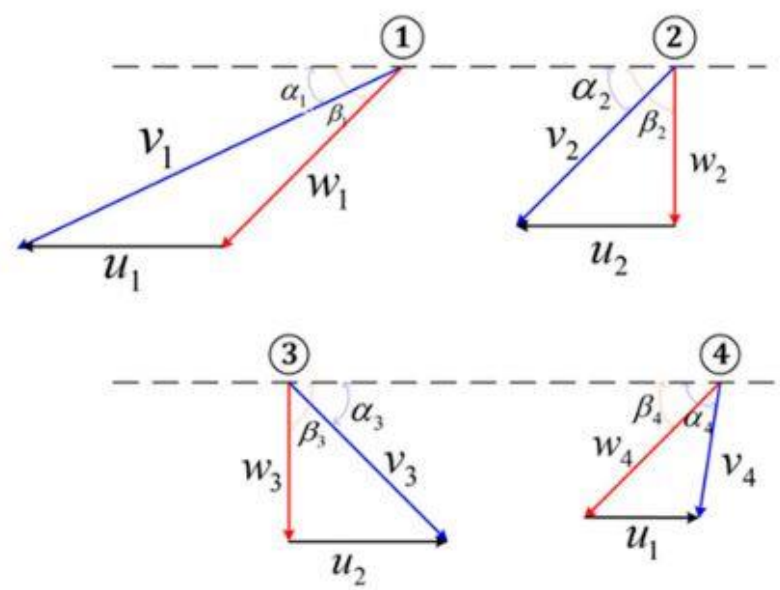

Figure 3. a) Fluid jet trajectory at different locations. b) Velocity triangles at locations 1-4. [12].

In a typical MBT design, the blades are assumed to be arcs of circumferences, which are defined by their $\beta_{1}$ and $\beta_{2}$ parameters and the runner inner-toouter-diameter ratio. If angle $\beta_{2}$ is assumed to be equal to $90^{\circ}$, it is not necessary to select other parameters (such as the opening angle of the blades or their radius) because they can be described as a function of other values, according to [7].

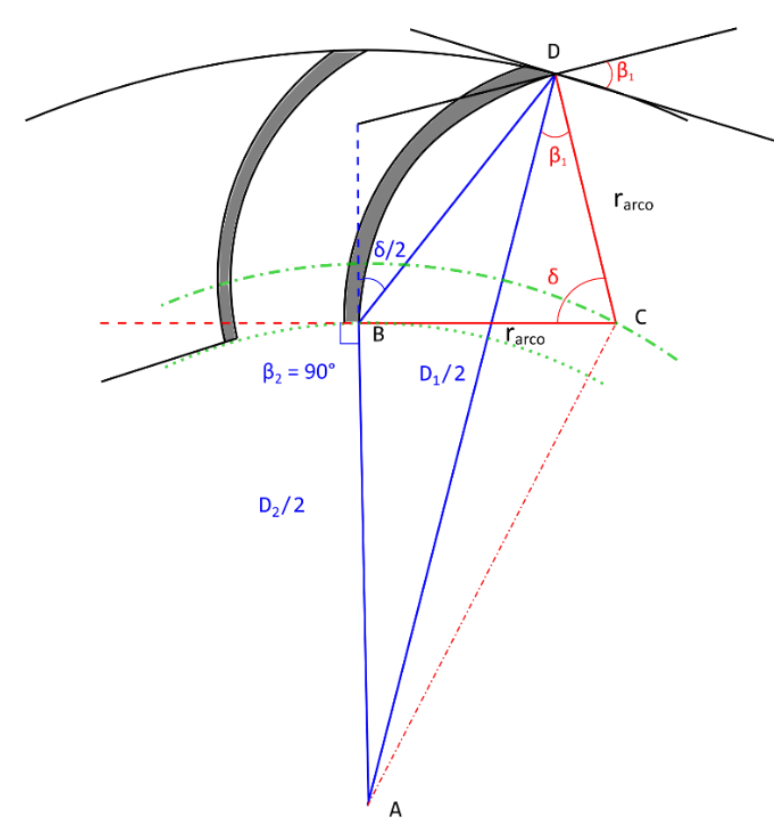

Figure 4. Geometric parameters of the blades in the turbine (adapted from [14]).

From Figure 4, it can be obtain

$$
r_{\text {arc }}=\frac{D_{1}^{2}-D_{2}^{2}}{4 \cdot D_{2} \cdot \cos \left(\beta_{1}\right)}
$$

Likewise, $\delta$ can be described in the same terms.

$$
\frac{D_{1}}{\sin \left(180-\frac{\delta}{2}\right)}=\frac{D_{2}}{\sin \left(90-\frac{\delta}{2}-\beta_{1}\right)}
$$

The equations above imply that every variable of the turbine can be described in terms of the inner and outer diameters of the runner and angle $\beta_{1}$.

\subsubsection{Sub-subsection}

To develop the physical formulation of the behavior of water inside the turbine, this study implemented the four assumptions below. They may not correspond to the real behavior of the system but to the conditions needed for an optimal performance.

1. The fluid is considered homogeneous, uncompressible, and in a steady state.

2. The energy contributions due to the difference in gravitational potential between the water inlet and outlet in the turbine are negligible.

3. The angle at which water leaves the turbine in the first stage is equal to the angle at which water enters the turbine in the second stage.

4. The loss coefficients equal 1 .

MBT efficiency $(\eta)$, defined as the ratio between the outlet power of the turbine and the inlet power of water, is described by equation (3). 


$$
\eta=\frac{-\tau \cdot \omega}{\rho \cdot g \cdot H \cdot Q}
$$

Where $\eta$ is the turbine efficiency, $\tau$ is the torque produced by the water, $\rho$ is the water density and $g$ is gravitational acceleration. For the optimization process, torque and angular velocity is calculated using the formulation by M.A. Chavez-Galarza [22].

The function below determines the torque applied by the water to the turbine runner using the moment of momentum equation in the control volume in Figure 5.

a)

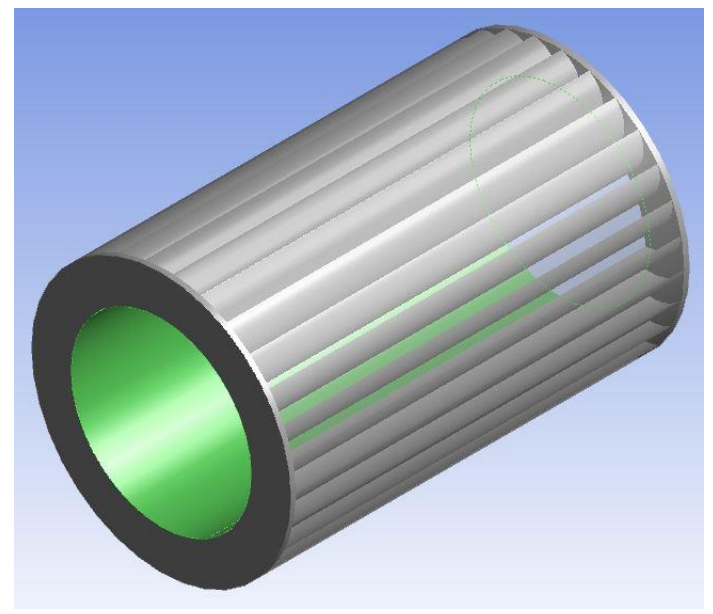

b)

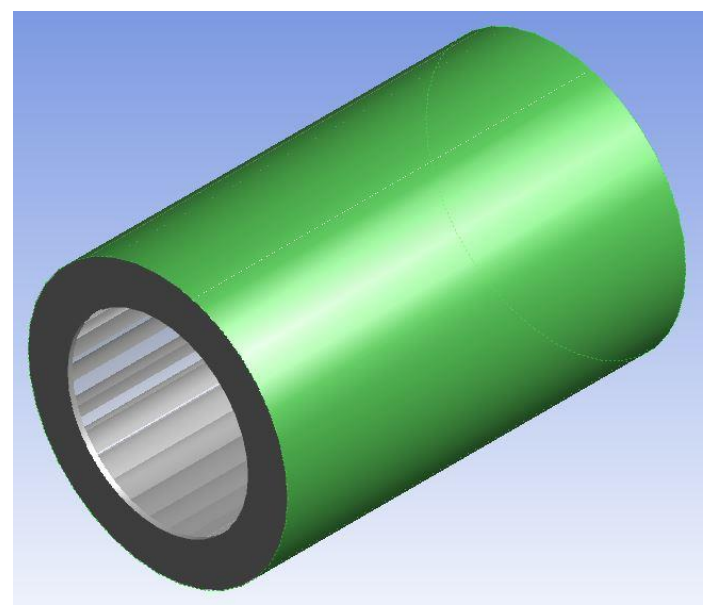

c)

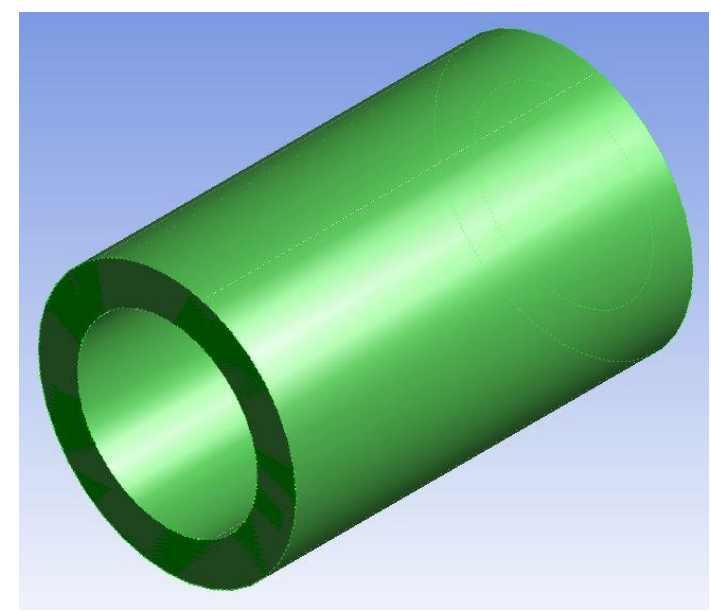

Figure 5. Proposed boundary conditions.

$$
\tau=\sum_{n=1}^{4}(-1)^{n} R_{n}^{2} \theta_{n} B \rho v_{n}^{2} \cos \left(\alpha_{n}\right) \sin \left(\alpha_{n}\right)
$$

Where $n$ is the location (1, 2, 3 or 4) from figure $3, \theta_{n}$ is the water arc, $B$ is the momentum-correction factor $=1, R_{1}$ and $R_{4}$ are the external runner radius, $R_{2}$ and $R_{3}$ are the internal runner radius, $\alpha_{n}$ is the angle between the velocity of the water and the tangent of the runner and $v_{n}$ is the absolute velocity.

If Assumptions 2 and 3 are applied to Equation (4) to cancel out the second and third terms of the Equation and $Q$ is defined, a flow rate and a torque equation can be presented as

$$
\begin{gathered}
Q=R_{1} \theta_{1} B v_{1} \sin \alpha_{1}=R_{1} \theta_{4} B v_{4} \sin \alpha_{4} \\
\tau=Q R \rho\left(v_{4} \cos \alpha_{4}-v_{1} \cos \alpha_{1}\right)
\end{gathered}
$$

Water velocity can be calculated using the energy conservation principle.

$$
V=\varphi \sqrt{2 g H}
$$

Where $\varphi$ is the loss coefficient associated with friction, which varies between 0.92 and 0.98 [22]; however, in this study, it equals 1 due to Assumption 4.

Replacing (6) and (7) in (3), we can obtain an equation that determines MBT efficiency as a function of both geometric and operating parameters:

$$
\eta=2 \frac{u_{1}\left(v_{1} \cos \alpha_{1}-v_{4} \cos \alpha_{4}\right)}{v_{1}^{2}}
$$

Where $u_{n}$ is the tangent velocity $=R_{n} \omega$.

The experimental results in the specialized literature revealed that the operating conditions, especially $Q$ and $H$, do not exert a great influence on MBT efficiency. For that reason, Equation (8) was 
simplified in order to obtain a numerical expression of efficiency as a function of the geometric parameters associated with the runner and the nozzle. Based on the velocity triangle in Figure 6 (which relates the fluid dynamics to the runner inlet and outlet), we obtained Equations (9) to (12).

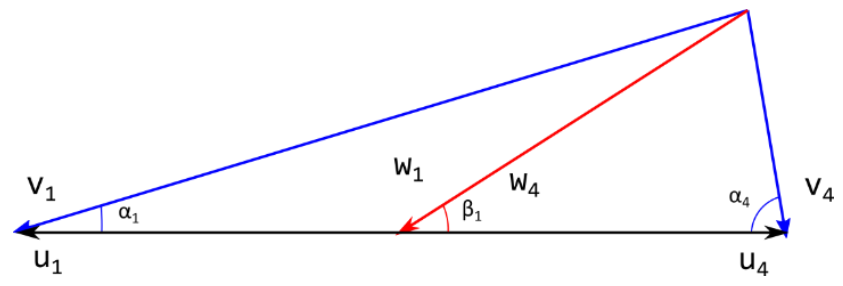

Figure 6. Velocity triangles from runner inlet to outlet [22].

$$
\begin{gathered}
v_{4} \cos \alpha_{4}=2 u_{1}-v_{1} \cos \alpha_{1} \\
w_{1} \cos \beta_{1}=v_{1} \cos \alpha_{1}-u_{1} \\
v_{1}^{2}=w_{1}^{2}+u_{1}^{2}+2 w_{1} u_{1} \cos \beta_{1} \\
\frac{u_{1}}{w_{1}}=\frac{\sin \left(\beta_{1}-\alpha_{1}\right)}{\sin \alpha_{1}}
\end{gathered}
$$

Where $\beta_{n}$ is the angle between the inlet of the blade and the tangent of the runner, $\omega$ is the angular velocity of the turbine, and $w_{n}$ is the absolute velocity.

Afterward, by replacing (9), (10), (11), and (12) in (8), it can be obtained Equation (13), which can be used to determine MBT efficiency as a function of the geometric parameters $\alpha$ and $\beta$ only.

$$
\eta=4 \frac{\sin \left(\alpha_{1}\right) \sin \left(\beta_{1}-\alpha_{1}\right) \cos \left(\beta_{1}\right)}{\sin ^{2}\left(\beta_{1}\right)}
$$

Equation (13) is thus the objective function in this optimization process to determine the maximum efficiency of the turbine.

\section{PSO Optimization}

Developed by Eberhart and Kennedy in 1995, a PSO algorithm replicates the behavior groups of animals (flocks of birds or schools of fish) searching for food sources [30]. Each particle represents an animal randomly placed in a solution space limited by constraints defined for a particular situation. PSO methods are characterized by the way particles move over the solution space: every single particle is affected by the maximum value obtained by itself as much as the maximum value obtained by the entire swarm. Furthermore, such methods can control the progress of the particles with a random component that prevents the algorithm from being trapped in local optima.

Importantly, the coordinates that define the position of the particles over the solution space correspond to the values of the parameters used to solve the objective equation. This technique has two versions: continuous and binary algorithms. This work implemented the continuous variant due to the nature of the equation and its variables, which are represented by real numbers.

The iterative process of the method is applied after the definition of the number of particles $(\mathrm{P})$ used to create a P-size set where it is possible to store the position of every particle denoted by vector $X_{i}$. The latter contains the variables (coordinates of the particle) to be optimized in the problem, as in Equation (14). Thus, a set of values associated with the optimal solution to the problem is found at the end of the iterative process. Likewise, the velocity vector $V_{i}$ contains the velocity of every particle, as shown in expression (15). Both vectors vary with every interaction, having the particles move closer to the maximum point in the domain. Additionally, such values are assigned between maximum and minimum allowable limits, which are relevant constraints determined for every case.

$$
\begin{array}{llll}
\boldsymbol{X}_{\boldsymbol{i}}=\left(\begin{array}{llll}
x_{i 1}, & x_{i 2}, & \cdots & x_{i n}
\end{array}\right), & \forall i \in P \\
\boldsymbol{V}_{\boldsymbol{i}}=\left(\begin{array}{llll}
v_{i 1}, & v_{i 2}, & \cdots & v_{i n}
\end{array}\right), & \forall i \in P
\end{array}
$$

Where $n$ denotes the number of dimensions or parameters to be optimized.

The position assigned to every particle, $X_{i n}$, is determined by the position of the particle at the previous iteration, $X_{i n}$, and the assigned velocity, $V_{i n}$, being $i$ the current iteration of the particle.

$$
X_{i d}=X_{i(d-1)}+V_{i d}
$$

Variable $V_{i d}$ is obtained from the values assigned to each variable at the previous iteration and the implementation of two adaptation functions. By analyzing the objective function of each particle, such functions can be used to identify the best position of the $\mathrm{i}$-th particle $\left(P_{\text {best }}\right)$ and the position of the best solution in the swarm of particles $\left(G_{\text {best }}\right)$ [31] in the following way:

$$
\begin{aligned}
V_{i d}=W V_{i(d-1)} & +c_{1} r_{1}\left(P_{b e s t, i}-X_{i(d-1)}\right) \\
& +c_{2} r_{2}\left(G_{\text {best }}-X_{i(d-1)}\right)
\end{aligned}
$$

Where $c_{1}$ and $c_{2}$ are the cognitive learning ratio (individual) and social ratio (group), respectively; $W$, an inertial coefficient; and $r_{1}$ and $r_{2}$, random numbers evenly distributed between 0 and 1 . Parameters $c_{1}$ and $c_{2}$ denote the relative importance of the memory (position) of the particle itself and the memory of the swarm, respectively [32].

Below is the flowchart of the PSO algorithm. 


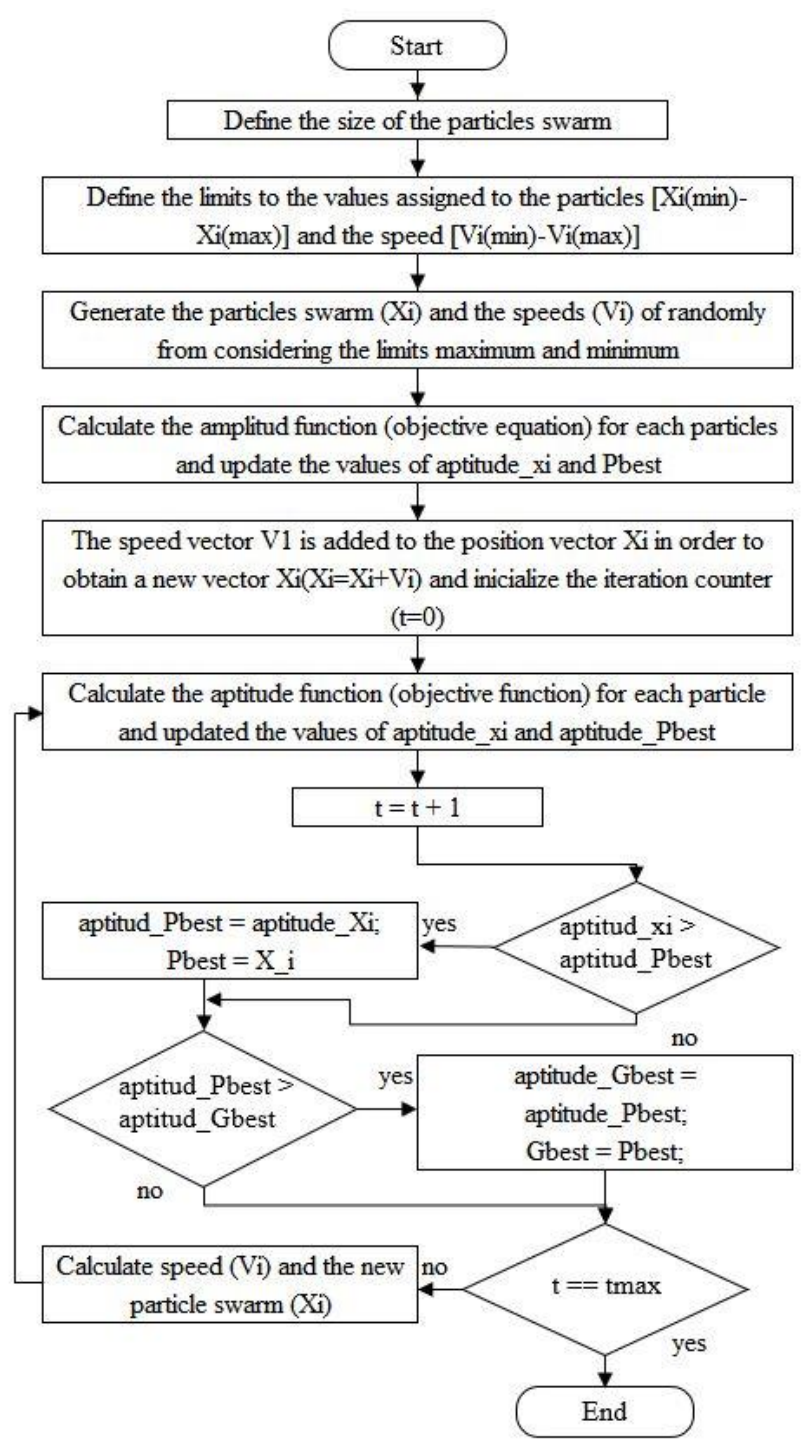

Figure 7. Flowchart of the PSO algorithm (adapted from [31]).

\section{Methodology}

The parameters to be optimized in this study are angles $\beta 1$ and $\alpha 1$ in Figure 3. With such angles, it is possible to calculate the tangential velocity of the turbine using its velocity triangle. The objective function of this problem was defined by Equation (13), which aims at maximizing MBT efficiency as a function of variables $\alpha_{1}$ and $\beta_{1}$. The constrains associated with the problem are defined in (18) and (19). The minimum and maximum values of $\alpha_{1}$ are $15^{\circ}$ and $24^{\circ}$, respectively [3]. The lower limit of $\beta_{1}$ is $15^{\circ}$ because the efficiency in Equation (13) is only negative if $\beta_{1}<\alpha_{1}$, and the maximum limit at $45^{\circ}$ enables a solution space wide enough to find the maximum value of the equation. Table 1 presents other terms used in this study to implement the algorithm.

$$
\begin{aligned}
& 15^{\circ}<\alpha_{1}<24^{\circ} \\
& 15^{\circ}<\beta_{1}<45^{\circ}
\end{aligned}
$$

Table 1. Parameters used in the optimization algorithm.

\begin{tabular}{cc}
\hline Parameter & Value \\
\hline$C_{1}$ & 1.5 \\
$C_{2}$ & 0.9 \\
$W$ & 0.4 \\
Iterations & 30 \\
Particles & 30 \\
\hline
\end{tabular}

The parameters of the optimization algorithm listed above are not the only ones that can produce an accurate solution. Nevertheless, with the values in Table 1, a solution to the problem was found in the shortest time, always ensuring a standard deviation below $1 \times 10-5$ in the results obtained after the algorithm was applied 10 times.

\section{Results}

In order to validate the accuracy of Equation (13), Table 2 shows other numerical and experimental efficiency results reported by different authors, as well as the error rates of the mathematical formulation proposed here and the method in [21] with respect to such results. From left to right, Table 2 presents authors and references; reported $\alpha_{1}$ and $\beta_{1}$; efficiency obtained experimentally or numerically; efficiency calculated using the method in [21]; efficiency calculated by Equation (13) proposed in this work; and absolute error rate, which is a comparison of the efficiency obtained by [21] and Equation (13) with the reported results.

Table 2. Numerical and experimental results in the literature compared to calculations using the method in

\begin{tabular}{|c|c|c|c|c|c|c|c|}
\hline Author & $\alpha\left(^{\circ}\right)$ & $\beta\left(^{\circ}\right)$ & $\begin{array}{l}\text { Reported } \\
\text { efficiency }\end{array}$ & $\begin{array}{l}\text { Efficiency } \\
\text { by [21] }\end{array}$ & $\begin{array}{c}\text { Efficiency } \\
\text { by Eq. } \\
\text { (13) }\end{array}$ & $\begin{array}{l}\text { (\%) Error } \\
\text { rate by }[21]\end{array}$ & $\begin{array}{c}\text { (\%) Error } \\
\text { rate by Eq. } \\
(13)\end{array}$ \\
\hline $\begin{array}{l}\text { A. J. Dakers and G. Martin } \\
\text { [33] }\end{array}$ & 22 & 30.0 & 0.69 & 0.8118 & 0.7224 & 17.65 & 4.70 \\
\hline W. Johnson et al [34] & 16 & 39.0 & 0.80 & 0.8765 & 0.8453 & 9.56 & 5.67 \\
\hline Y. Nakase et al[35] & 15 & 39.0 & 0.82 & 0.8854 & 0.8263 & 7.98 & 0.77 \\
\hline S. Khosrowpanah et al. [36] & 16 & 39.0 & 0.80 & 0.8765 & 0.8453 & 9.56 & 5.67 \\
\hline
\end{tabular}
[21] and Equation (13) in this work. 
A. A. Fiuzat and B. Akerker [37]
[8ai and N. M. Aziz

V. R. Desai a

[8]

H. G. S. Totapally and N. M. Aziz [38]

V. Sammartano et al. [39]

$24 \quad 39.0$

0.89

0.7862

0.8263

11.66

7.16

$\begin{array}{lll}22 & 39.0 & 0.88\end{array}$

0.8118

0.8597

7.75

2.31

$\begin{array}{lll}22 & 39.0 & 0.90\end{array}$

0.8118

0.8597

9.80

4.48

Y.C. Ceballos et al. [19]

$\begin{array}{lll}22 & 38.9 & 0.86\end{array}$

0.8118

0.8597

5.60

0.04

$\begin{array}{lll}22 & 40.0 & 0.86\end{array}$

0.8118

\begin{tabular}{cc} 
Average & 9.46 \\
\hline $\begin{array}{c}\text { Standard } \\
\text { Deviation }\end{array}$ & 3.66 \\
\hline
\end{tabular}

0.18

Y.C. Cebalos eta $[19]$

In Table 2, the maximum absolute errors produced by Equation (13) and the methodology proposed in [21] were $7.16 \%$ and $17.65 \%$, respectively, in relation to the efficiencies reported in the specialized literature. However, the performance of the two mathematical formulations in Table 2 is different. The method proposed in this paper produces a reduction of $64 \%$ in the average error rate (3.44) compared to that of the mathematical formulation in [21] (9.46). Thus, the proposed formulation demonstrates to be an excellent tool for calculating MBT efficiency in a numerical form.

In addition, this work implemented a PSO algorithm to solve the mathematical formulation presented in Section 5, where $\alpha_{1}$ and $\beta_{1}$ equal $15^{\circ}$ and $28.186^{\circ}$, respectively. Finally, a maximum MBT efficiency of $93.3 \%$ was obtained. This theoretical result is better than the output reported in the references used in this study. In this case, the simulation was carried out on an Intel ${ }^{\circledR}$ core ${ }^{\mathrm{TM}}$ I 7-5500U desktop computer with $8 \mathrm{~GB}$ of RAM using the software MATLAB R2019b®.

\section{Conclusions}

This paper described the development of a new methodology for calculating the optimal angle of attack and blade position of an MBT in order to achieve its maximum efficiency. To improve its hydraulic efficiency, the authors proposed a mathematical formulation based on the moment of momentum equation and a PSO algorithm as solution method. Such formulation produced a maximum uncertainty of $7.16 \%$ and a standard deviation of $2.67 \%$ compared to the literature; additionally, it reduced the absolute average error by $64 \%$ compared to the method in [21].

Angle $\alpha_{1}$ was found to have a considerable influence on MBT efficiency, and its ideal value is $15^{\circ}$ for an optimal performance of the turbine in the proposed domain, from $15^{\circ}$ to $24^{\circ}$. The ideal angle $\beta_{1}$ is $28.186^{\circ}$. A theoretical efficiency of $93.3 \%$ was obtained with those parameters.
The PSO method was successfully adapted to the objectives of this study, and it found an optimal value in a very short time (compared to CFD calculations) when it solved the efficiency equation 900 times. In conclusion, an optimization method and a computer with limited specifications can obtain fast results, which is not possible with CFD techniques.

\section{References:}

[1] E. E. Gaona, C. L. Trujillo, and J. A. Guacaneme, "Rural microgrids and its potential application in Colombia," Renew. Sustain. Energy Rev., 2015.

[2] L. D. Claxton, "The history, genotoxicity, and carcinogenicity of carbon-based fuels and their emissions: Part 5. Summary, comparisons, and conclusions," Mutat. Res. Rev. Mutat. Res., vol. 763, pp. 103-147, 2015.

[3] R. Adhikari and D. Wood, "The Design of High Efficiency Crossflow Hydro Turbines: A Review and Extension," Energies, vol. 11, no. 2, p. 267, 2018.

[4] M. Sinagra, V. Sammartano, G. Morreale, and T. Tucciarelli, "A New Device for Pressure Control and Energy Recovery in Water Distribution Networks," Water, vol. 9, no. 5, p. 309, 2017.

[5] J. De Andrade, C. Curiel, F. Kenyery, O. Aguill, and M. Asuaje, "Numerical Investigation of the Internal Flow in a Banki Turbine," Int. J. Rotating Mach., vol. 2011, 2011.

[6] J. I. Goméz Gómez, E. A. Palacio Higuita, and C. A. Paredes Gutiérrez, "La turbina Michell-Banki y su presencia en Colombia," Av. Recur. Hidraul., vol. 17, pp. 33-42, 2008.

[7] C. A. Mockmore and F. Merryfield, "Banki Water Turbine," no. February, 1949.

[8] V. R. Desai and N. M. Aziz, "Parametric Evaluation of Cross-Flow Turbine Performance," J. Energy Eng. - ASCE, vol. 120, no. 1, pp. 17-34, 1994.

[9] H. Olgun, "Investigation of the performance 
of a cross-flow turbine," Int. J. Energy Res., vol. 22, no. 11, pp. 953-964, 1998.

[10] M. Sinagra, V. Sammartano, C. Aricò, A. Collura, and T. Tucciarelli, "Cross-Flow turbine design for variable operating conditions," Procedia Eng., vol. 70, pp. 1539-1548, 2014.

[11] R. Adhikari, J. Vaz, D. Wood, R. C. Adhikari, J. Vaz, and D. Wood, "Cavitation Inception in Crossflow Hydro Turbines," Energies, vol. 9, no. 4, p. 237, Mar. 2016.

[12] E. T. Woldemariam, H. G. Lemu, and G. G. Wang, "CFD-Driven Valve Shape Optimization for Performance Improvement of a Micro Cross-Flow turbine," no. January, 2018.

[13] C. L. Rantererung, S. Soeparman, R. Soenoko, and S. Wahyudi, "IMPROVEMENT OF PERFORMANCE CROSS FLOW TURBINE WITH DUAL NOZZLE," ARPN J. Eng. Appl. Sci., vol. 13, no. 7, pp. 2364-2368, 2018.

[14] M. Cardona, "Desarrollo de un Método de Diseño y Análisis por Simulación Numérica de de Acción de Flujo Cruzado para Pico Centrales Hidroeléctricas," 2016.

[15] A. Dragomirescu, "Numerical investigation of the flow in a modified Bánki turbine with nozzle foreseen with guide vanes," Proc. 2016 Int. Conf. Expo. Electr. Power Eng. EPE 2016, no. Epe, pp. 874-879, 2016.

[16] M. A. A. Vilchez, "Geometría del álabe del rotor para mejorar el torque en una turbina Michell-Banki," Universidad Nacional del Centro de Perú, 2015.

[17] B. Budiarso, D. Adanta, and A. I. Siswantara, "Comparison between Airfoil NACA-6712 Profiled and Ordinary Blade in Cross-flow Turbine by Numerical Simulation," in 15th International Conference on Quality in Research, 2017, no. September.

[18] D. Adanta, A. I. Siswantara, and A. P. Prakoso, "Performance Comparison of NACA 6509 and 6712 on Pico Hydro Type Cross- Flow Turbine by Numerical Method," J. Adv. Res. Fluid Mec. Therm. Sci., no. May, 2018.

[19] Y. Castañeda-Ceballos, M. CardonaValencia, D. Hincapie-Zuluaga, and J. Sierra-Del, "Influence of the Number of Blades in the Power Generated by a Michell Banki Turbine," Int. J. Renew. Energy Res., vol. 7, no. 4, 2017.

[20] L. Jasa, R. I. Putri, P. N. Malang, A. Priyadi, and M. H. Purnomo, "Design Optimization Of Micro Hydro Turbine Using Artificial Particle Swarm Optimization And Artificial Neural Network," KURSOR J., no. October, 2014.

[21] L. Jasa, I. P. Ardana, A. Priyadi, and M. H. Purnomo, "Investigate Curvature Angle of the Blade of Banki's Water Turbine Model for Improving Efficiency by Means Particle Swarm Optimization," Int. J. Renew. Energy Res., vol. 7, no. 1, pp. 170-177, 2017.

[22] M. A. Chavez-Galarza, "Un Estudio de la Turbina de Flujo Cruzado (Efecto del Ángulo de Ataque y el ángulo de entrada del álabe y Relación de Diametros en la Eficiencia Hidráulica)," Universidad Nacional de Trujillo, 2013.

[23] M. C. Potter, D. C. Wiggerts, M. Hondzo, and T. I. P. shih, Mechanics of Fluids, 3rd editio. Mexico D.F., 2002.

[24] S. Mirjalili, J. S. Dong, A. Lewis, and A. S. Sadiq, "Particle Swarm Optimization: Theory, Literature Review, and Application in Airfoil Design," Nat. Inspared Optim., vol. 811, pp. 167-184, 2019.

[25] S. Phommixay, M. Lamine, D. David, and L. St, "Review on the cost optimization of microgrids via particle swarm optimization," Int. J. Energy Environ. Eng., vol. 11, no. 1, pp. 73-89, 2020.

[26] J. F. Jaramillo Velez and L. F. Grisales Noreña, "Sintonización del d-statcom por medio del método de optimización pso," Universidad Tecnológica de Pereira, 2013.

[27] N. Eltawil, M. Sulaiman, M. Shamshiri, and Z. Bin Ibrahim, "Optimum Allocation of Capacitor and DG in MV Distribution Network Using PSO and OpenDSS," ARPN J. Eng. Appl. Sci., vol. 14, no. 2, pp. 363371, 2019.

[28] A. Shourangiz-Haghighi et al., "State of the Art in the Optimisation of Wind Turbine Performance Using CFD," Arch. Comput. Methods Eng., vol. 1, p. 3, 2019.

[29] C. Akan, M. F. Aksit, S. Aksoy, and E. Yuksel, "Response Surface Modeling of a Small Crossflow Hydro Turbine Rotor," 2008.

[30] J. Kennedy and R. Eberhart, "Particle swarm optimization," Neural Networks, 1995. Proceedings., IEEE Int. Conf., vol. 4, pp. 1942-1948 vol.4, 1995.

[31] O. D. Montoya, J. Andres, and S. Del, "Optimization of a Drive Shaft using PSO Algorithm," WSEAS Trans. Appl. Theor. 
Mech., vol. 13, pp. 130-139, 2018.

[32] S. S. Rao, Engineering Optimization. 2009.

[33] A. J. Dakers and G. Martin, "Development of a Simple Cross-Flow turbine for Water Turbine for Rural Use.," Natl. Conf. Publ. Inst. Eng. Aust., no. 82 /8, pp. 35-42, 1982.

[34] W. Johnson, E. R. White, and F. White, "Design and testing of an inexpensive crossflow turbine," ASME, 1982.

[35] Y. Nakase, J. Fukutomi, T. Watenebe, T. Suetsugu, T. Kubota, and S. Kushimoto, "A study of Cross-Flow turbine (Effects of nozzle shape on its performance)," ASME, vol. 1419, 1982.

[36] S. Khosrowpanah, A. Fiuzat, and M. L. Albertson, "Experimental Study of crossflow turbine.," J. Hydraul.

[37] A. A. Fiuzat and B. Akerkar, "The Use of Interior Guide Tube in Cross Flow Turbines." ASCE, pp. 1111-1119, 1989.

[38] H. G. S. Totapally, N. M. Aziz, and H. G. S., "Refinement of Cross-Flow Turbine Design Parameters," vol. 120, no. 3, pp. 133-147, 1995.

[39] V. Sammartano, C. Aricò, A. Carravetta, O. Fecarotta, and T. Tucciarelli, "Banki-Michell Optimal Design by Computational Fluid Dynamics Testing and Hydrodynamic Analysis," Energies, vol. 6, no. 5, pp. 2362 2385, Apr. 2013.

\section{Contribution of individual authors to the creation of a scientific article (ghostwriting policy)}

Author Contributions: Please, indicate the role and the contribution of each author:

Example

J. Sierra-Del Rio and S. Galvis contributed with the knowledge of the Banki turbine and the mathematical formulation.

A. Pérez-Rodríguez and L. F. Grisales-Noreña contributed with the knowledge of PSO method and programation.

Follow: www.wseas.org/multimedia/contributor-

role-instruction.pdf

\section{Sources of funding for research presented in a scientific article or scientific article itself}

Report potential sources of funding if there is any

\section{Creative Commons Attribution \\ License 4.0 (Attribution 4.0 \\ International , CC BY 4.0)}

This article is published under the terms of the Creative Commons Attribution License 4.0 https://creativecommons.org/licenses/by/4.0/deed.en US 